\title{
Characterization of Equid Herpesvirus 1 (EHV-1) Related Viruses from Captive Grevy's Zebra and Blackbuck
}

\author{
Kerstin BORCHERS ${ }^{1)}$, Daniel BÖTTNER ${ }^{1)}$, Dietmar LIECKFELDT ${ }^{1)}$, Arne LUDWIG ${ }^{1)}$, Kai FRÖLICH ${ }^{2}$, \\ Berndt KLINGEBORN ${ }^{1)}$, Frederik WIDÈN ${ }^{4)}$, George ALLEN ${ }^{3)}$ and Hanns LUDWIG ${ }^{1)}$ \\ ${ }^{1)}$ Institut für Virologie, FU Berlin, Königin-Luise-Str. 49, 14195 Berlin, Germany, ${ }^{2}$ Leibniz-Institute for Zoo and Wildlife Research \\ Berlin, P.O. Box 601103, 10252 Berlin, Germany, ${ }^{3)}$ Department of Veterinary Science, Gluck Equine Research Center, Universitiy of \\ Kentucky, Lexington, U.S.A. and ${ }^{4)}$ Department of Virology, The National Veterinary Institute, (SVA), Uppsala, Sweden
}

(Received 2 November 2005/Accepted 7 March 2006)

ABSTRACT. Equid herpes virus 1 (EHV-1) related isolates from a captive blackbuck (strain Ro-1) and Grevy's zebra (strain T965) behaved similarly to EHV-1 and EHV-9 in respect to their host cell range. Restriction enzyme analysis and a phylogenetic tree confirmed that Ro-1 and T965 were identical and more closely related to EHV-1 than to EHV-9. Differences from EHV-1 became obvious firstly, by amino acid alignments revealing two unique substitutions in the gB protein of Ro-1 and T965. Secondly, an EHV-1 type-specific monoclonal antibody did not detect its antigen on Ro-1, T965 or EHV-9 infected cells by immunohistochemistry. The results support the view that Ro-1 and T965 isolates represent a distinct, previously unrecognized species of equid herpesviruses.

KEY WORDS: antelope, equid alphaherpesvirus, zebra.

Equids serve as hosts for six alphaherpesviruses (Equid herpesvirus 1 (EHV-1), EHV-3, -4, -6, -8 and -9). EHV-1, -3 and -4 are important viral pathogens of domestic horses, causing equine abortion, neonatal foal disease, neurological disease (EHV-1), rhinopneumonitis (EHV-4) [for reviews 6, 14], and equine coital exanthema (EHV-3) [10]. EHV-6 and -8 represent donkey viruses also known as asinine herpesvirus-1 and -3 [8, 11], whereas EHV-9 represents a neurotropic EHV-1 related herpesvirus isolated from a captive Thomson's gazelle (Gazella thomsoni) [9].

It is well known that herpesviruses closely related to EHV-1 can infect not only different captive species of zoo equids (Przewalski's wild horse, Damara zebra, Grant's zebra, Burchell's zebra, onager and domestic ass) but also non-equid species (fallow deer, cattle, blackbuck, alpacas, llamas and Thomson's gazelles) $[5,7,17]$. Herpesvirus isolates from such infections include those from an aborted onager fetus at the National Zoo in Washington, a Grevy's zebra fetus (strain T965) from the Lincoln Park Zoo in Chicago, a blackbuck (Antelopa cervicapra) (strain Ro-1) at Kolmarden zoological garden, Sweden, the brain of a Thomson's gazelle at the Knoxville Zoological Park and from a recent outbreak of acute encephalitis in a captive herd of Thomson's gazelles at a zoological garden in Japan $[5,9,12,15,22]$. The latter was initially attributed to gazelle herpesvirus type 1 (GHV-1), but was later classified as EHV-9 based on DNA identity in the genes encoding glycoproteins B and G of $97.5 \%$ and $92.4 \%$ to EHV-1, respectively, but differences in regard to their restriction enzyme cleavage profiles [9].

When comparing such published restriction enzyme analysis of isolates from equid and non-equid species [4, 5, 9, $12,15,22]$, we made the following observations: Firstly, the DNA cleavage patterns are similar among all the isolates but different from those of EHV-1. Secondly, the restriction enzyme cleavage patterns segregated into two groups, suggesting the existence of two equid herpesvirus species. On the one hand, the restriction enzyme cleavage pattern of the abortigenic onager (strain T529) and neuropathogenic gazelle isolates from the American zoos seemed to be identical to each other and only slightly different from the recent gazelle isolate from Japan (Fukushi, personal communication). On the other hand, the abortion strain from a Grevy's zebra and the neuropathogenic blackbuck strain formed a second cluster with shared restriction enzyme cleavage patterns. These observations should be taken into account not only in respect to the host but also the pathogenic range of EHV-1 related virus strains when searching for the natural host of these EHV-1 related viruses.

Recently, we analyzed Burchell's zebra sera from the Serengeti National Park and found a statistically significant high number of animals with antibodies against EHV-9, but negative for antibodies against EHV-1 and the zebra isolate T965 [3]. In contrast, archived sera from free-ranging Mountain zebras (Equus zebra) from Namibia [2] were positive against both EHV-1 and EHV-9 and in rare cases also against the Grevy's zebra strain [3]. These investigations reinforced questions on origin and relationship of EHV-1like strains from different equid and non-equid species. To get further insight to these problems, we conducted virological and molecular biological comparisons of the Grevy's zebra strain T965 and the blackbuck strain Ro-1 with EHV1, EHV-4 and EHV-9.

Mar87 is an abortigenic EHV-1 strain and T252 a respiratory isolate defined as EHV-4 by P. Thein (München, Germany). EHV-9 was kindly supplied by H. Fukushi (Department of Veterinary Microbiology, Faculty of Agriculture, Gifu University, Yanagido, Japan). The late G. Rockborn (Department of Virology, The National Veterinary Institute, (SVA), Uppsala, Sweden) had kindly sup- 
plied Ro-1. This virus originated from the brain of a blackbuck, which had died with signs of malignant catarrhal fever. All these virus strains were propagated on equine dermal (ED) cells and plaque purified three times. With the exception of EHV-4, all strains could be grown on several other cell lines, such as rabbit kidney (RK13) and rabbit spleen cells, Mardin-Darby bovine kidney (MDBK) as well as Crandle feline kidney (CRFK) cells. Interestingly, in common with the compared EHV-1 related strains, EHV-9 could not be propagated on Mardin-Darby canine kidney (MDCK) cells. This is contrary to the wide in vivo host range of EHV-9 as shown by experimental infection of mice, goats, pigs, cats and dogs $[9,16,18,20,21]$.

For genomic analysis and differentiation, virus from supernatants of infected ED cells was pelleted by ultra-centrifugation through a $20 \%$ succrose cushion, and viral DNA was extracted using the RTP DNA/RNA virus mini kit (Invitek, Berlin, Germany); 200 ng of purified viral DNA was digested with the restriction enzymes $B g l I I, B a m H I$ and EcoRI, respectively, according to the manufacturer's instructions. Fragments were separated by electrophoresis through $0.7 \%$ agarose gels and stained with ethidium bromide. Figure 1 shows that, with all three enzymes, the resulting cleavage patterns of T965 and Ro-1 DNA were identical to one other, but slightly different from those of EHV-1 and EHV-9.

For amplification of EHV-1 gB gene fragments, we used a nested PCR described elsewhere [1] which cross-reacts with Ro-1, T965 and EHV-9, but not with EHV-4. The resulting PCR product spans a $1.28 \mathrm{~kb}$ region of the gB gene (EHV-1 gene position 2329-3604). For comparative analysis, sequencing of $\mathrm{gB}$ was done using the same primers described earlier [1] and a fluorescent-labelled BigDye Cycle Sequencing Kit (ABI, U.S.A.). PCR amplification products were purified by treatment with ExoSAP-IT (USB Corporation, U.S.A.) and followed by fragment separation on a 3100 Genetic Analyzer (ABI) according to manufacturer's instructions.

We sequenced an $1175 \mathrm{bp}$ portion of the gB gene. The corresponding positions within the complete genome sequence of the EHV-1 strain V592 (Accession Nr. AY464052) are 62805 to 63979 . Several available gB gene sequences of other equine herpesviruses were obtained from DNA databases for sequence comparisons and phylogenetic reconstructions (accession numbers in brackets: EHV-1 strains V592 [AY464052], Racl11 [X95374], RacH [X95377], Ab1 [M36298], Ab4 [AY665713], HVS25A [D00401] and two sequences without strain names [M34861], [M35145]; EHV-4 strains NS80567 [AF030027] and one sequence without strain name [M26171]; EHV-9 strain GHV1 [D49800]). The gB gene sequences of the EHV-1 strain Mar87, blackbuck strain Ro-1 and Grevy's zebra strain T965, generated in this study, were stored in Gene Bank [DQ095871, DQ095872, DQ095873].

Sequence alignments were done using CLUSTAL W [19] and proofed visually. We used the computer package MEGA v. 2.1 [13] to calculate nucleotide Kimura 2-param-
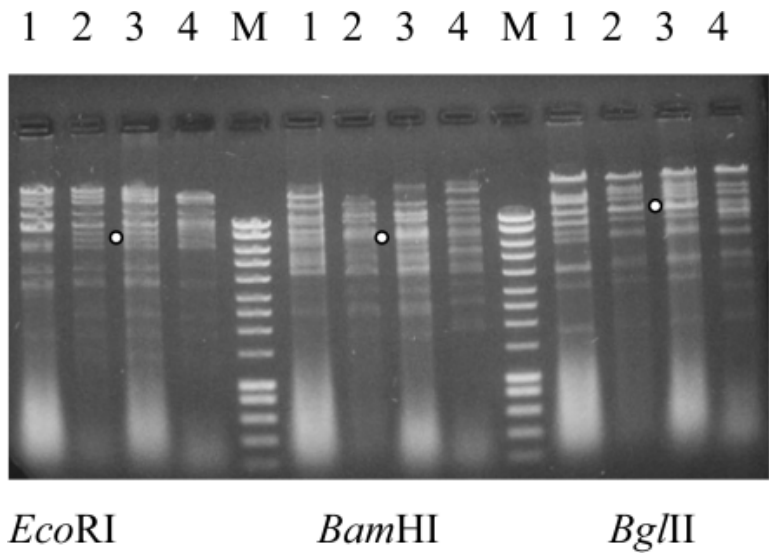

Fig. 1. Restriction enzyme analysis of EHV-1, Ro-1, T965 and EHV-9 (lanes 1, 2, 3 and 4, respectively) with EcoRI, BamHI, $B g l I I$. Fragments unique to strains Ro-1 and T965 are marked with a dot. As marker a hyper ladder from Bioline were used.

eter distances, amino acid p-distances and neighbor joining trees. The significance of the branches was examined by bootstrap analysis (1000 replications) as implemented in MEGA.

Within our complete nucleotide alignment of the gB gene sequences, we detected 221 variable sites. Phylogenetic reconstructions show that the $\mathrm{gB}$ sequences of Ro-1 and T965 are identical and form their own unique branch $(87 \%$ and $79 \%$ bootstrap support from reconstructions with nucleotide and amino acid distances respectively) with a basal position to the EHV-1 cluster $(100 \% ; 70 \%)$. According to all available EHV groups, the position of Ro-1/T965 is intermediate amongst EHV-4 and EHV-9 on the one site and EHV-1 on the other (Fig. 2).

At the amino acid level, Ro-1 and T965 are identical and more closely related to EHV-1 (99\%) than to EHV-9 (97.1\%) or to EHV-4 (93.3\%). In comparing EHV-9 with EHV-1 and EHV-9 with EHV-4, amino acid identities of $97.1 \%$ and $92.6 \%$, respectively, were determined. Interestingly, the 391 amino acid sequence of Ro-1 and T965 contains at position 29 and 183 unique substitutions (Fig. 3) which are missing in all the other virus strains analyzed so far.

Immunohistochemistry revealed an additional difference between Ro-1/T965 and the other herpesvirus isolates. ED cells were infected with 50 plaque-forming units (PFU) of the respective virus per well of a 96 -well microtiter plate. After 2 days of incubation cells were fixed in phosphate buffered saline (PBS) containing 4\% formalin and for permeabilisation, subsequently treated with $1 \%$ Triton-X-100 in PBS. The EHV-1 type-specific monoclonal antibody Ai2G7, directed against a $280 \mathrm{kd}$ glycoprotein, which most probably represents gp2 (Borchers and Reuter, unpublished), and as control, an EHV-1 gB specific monclonal antibody (Ai11C10) were used for antigen dection. Horseradish peroxidase-conjugated goat anti-mouse $\mathrm{IgG}$ (Dianova, Hamburg, Germany) and the appropriate sub- 


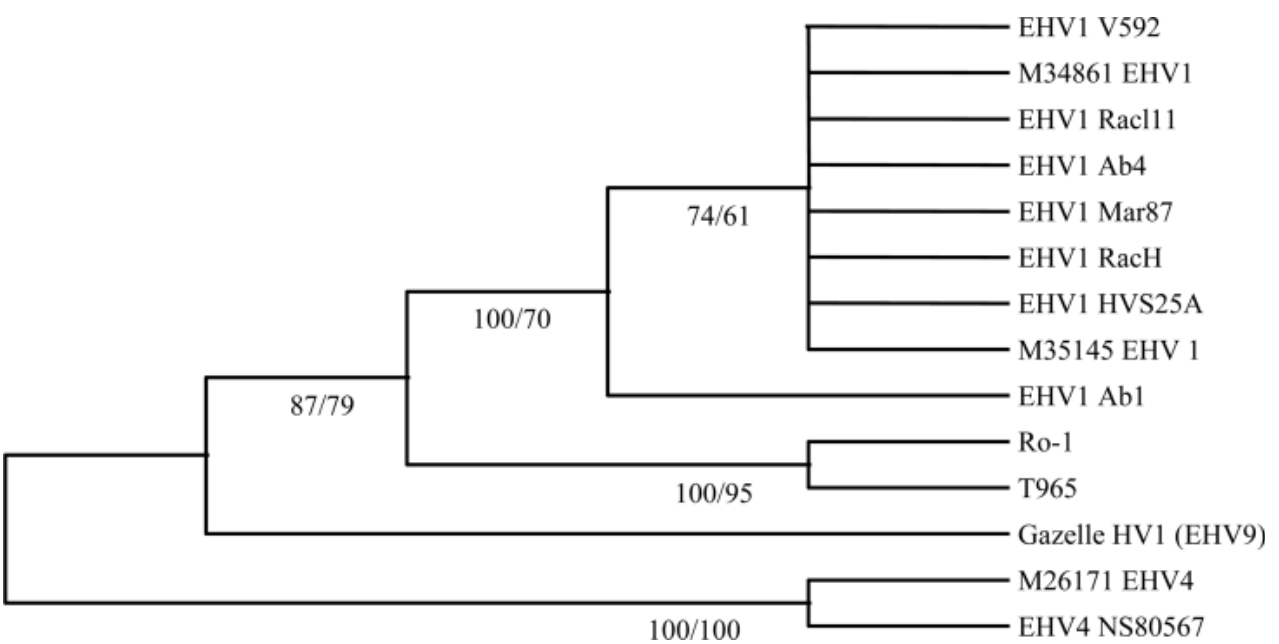

Fig. 2. Neighbor-Joining consensus tree based on gB sequences. Only branches above $50 \%$ bootstrap support (1000 replicates) are shown. The same tree topology resulted from tree reconstructions with nucleotides and with amino acids. Numbers indicate bootstrap support of branches from nucleotide/amino acid trees.

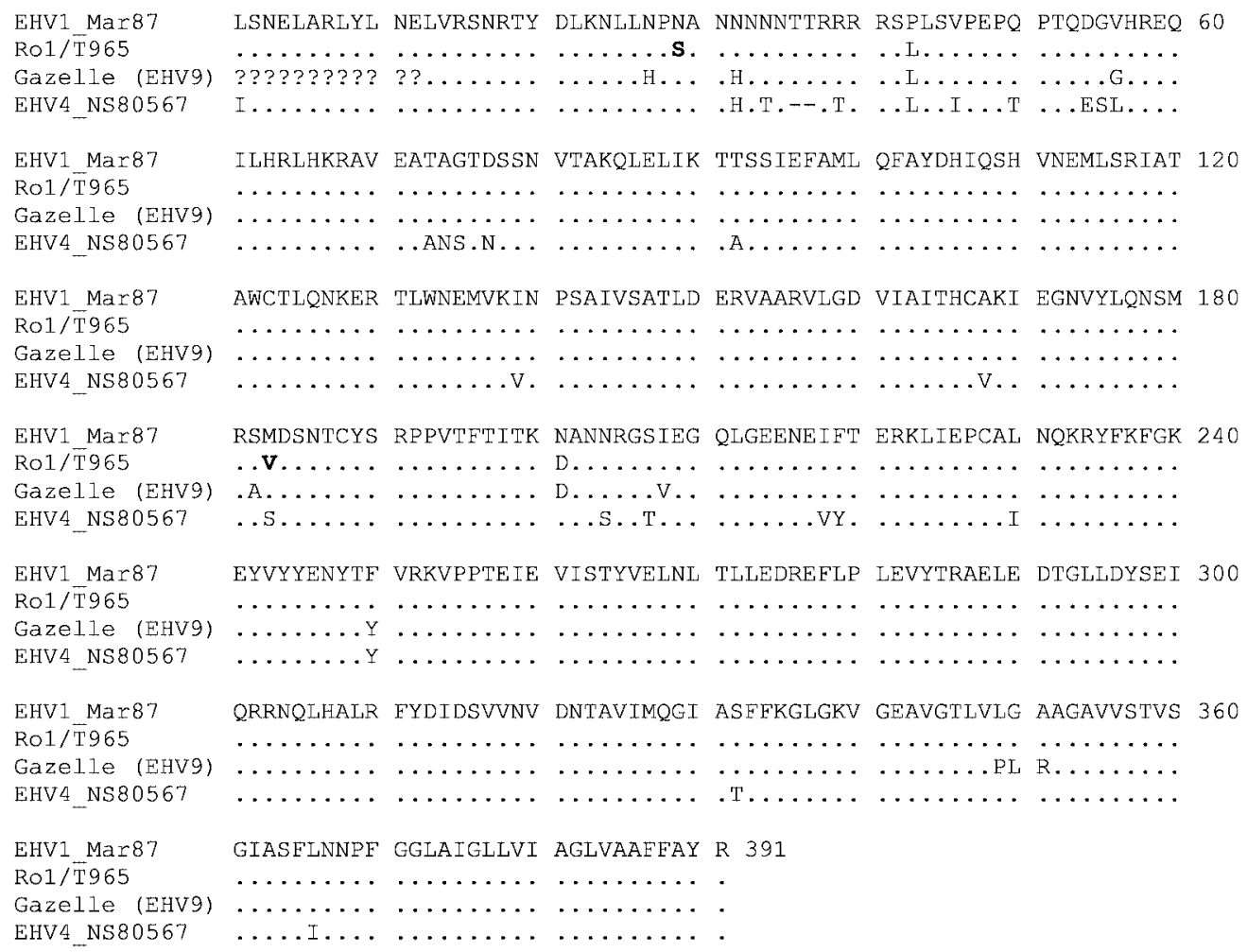

Fig. 3. Amino acid sequence alignment of equid herpesvirus gB sequences. Substitutions unique to virus isolates Ro-1 and T965 are indicated in bold letters. Dots represent concordance, hyphens gaps and question marks stand for unavailable sequences.

strate were used for visualization of antigen-antibody reactions. Ai2G7 detected its epitope as expected on EHV-1specific plaques, but not on cells infected with Ro-1, T965, EHV-9 or EHV-4. In contrast, Ai11C10 cross-reacted with all the EHV-1 related strains including EHV-4 (data not pre- sented).

Taken together, our biological and molecular biological studies revealed that the neurotropic and abortigenic strains Ro-1 and T965 from captive blackbuck and Grevy's zebra, respectively, are identical to each other and very similar to 
EHV-1 and EHV-9. Evidence for this came from amino acid sequence alignments of $\mathrm{gB}$ and a deduced phylogenetic evolutionary tree. There are, however, some properties, which demonstrates that Ro-1 and T965 strains form a unique species: 1 . The amino acid sequence of $\mathrm{gB}$ contains two diagnostic substitutions; 2. By immunohistochemistry, an EHV-1 type-specific immunogenic epitope was not detectable on Ro-1 and T965 infected cells; 3. More obviously, Ro-1 and T965 are genomically different from EHV1 and EHV-9 as shown by restriction enyzme analysis.

In conclusion, we postulate, firstly, that the onager and Thomson's gazelle isolates of EHV-1-like viruses represent EHV-9 and, secondly, that the Grevy's zebra and blackbuck virus strains are identical to each other and different from all currently recognized types of equid herpesviruses. Furthermore, differences in their restriction enzyme cleavage profiles, their $\mathrm{gB}$ sequences and immunogenic epitopes has prompted us to propose that the blackbuck and Grevy's zebra strains represent a distinct species of equid herpesviruses. Given the observation that these new strains like EHV-9 in zoo equids were abortigenic and in the non-equid host neuropathogenic and that the natural host of both herpesviruses is still unknown, it seems advisable that, in zoological parks, caution should be taken keeping not only different equid species but also equid and non-equid ungulate species together.

ACKNOWLEDGMENTS. We acknowledge T. Leiskau, A. Büchel and A. Reum for excellent technical assistence. We thank Bengt Röken and Torsten Mörner for providing us with samples.

\section{REFERENCES}

1. Borchers, K. and Slater, J. 1993. J. Virol. Meth. 45: 331-336.

2. Borchers, K. and Frölich, K. 1997. J. Wildlife Dis. 33: 812817.

3. Borchers, K., Wiik, H., Frölich, K., Ludwig, H. and East, M. 2005. J. Wildlife Dis. 41: 80-86.

4. Chowdhury, S. I., Kubin, G. and Ludwig, H. 1986. Arch. Virol.
90: $273-288$.

5. Chowdhury, S. I., Ludwig, H. and Buhk, H.-J. 1988. Virus Res. 11: $127-129$.

6. Crabb, B. S. and Studdert, M. J. 1995. Adv. Virus Res. 45: 153189.

7. Crandell, R. A., Ichimura, H. and Kit, S. 1988. Am. J. Vet. Res. 49: $1807-1813$.

8. Ficorilli, N., Studdert, M. J. and Crabb, B. S. 1995. Arch. Virol. 140: $1653-1662$.

9. Fukushi, H., Tomita, T., Taniguchi, A., Ochiai, Y., Kirisawa, R., Matsumura, T., Yanai, T., Masegi, T., Yamaguchi, T. and Hirai, K. 1997. Virology 226: 34-44.

10. Hartley, C. A., Drummer, H. E. and Studdert, M. J. 1999. Arch. Virol. 144: 2023-2033.

11. Jacob, R. J., Cohen, D., Bouchey, D., Davis, T. and Borchelt, J. 1988. pp. 140-146. In: Equine Infectious Diseases V, Proceedings of the Fifth International Conferences on Equine Infectious Diseases, University Press of Kentucky, Lexington.

12. Kennedy, M. A., Ramsay, E., Diderrich, V., Richman, L., Allen, G. P. and Potgieter, B. 1996. J. Zoo Wildlife Med. 27: 533-538.

13. Kumar, S., Tamura, K. and Nei, M. 1994. Comput. Appl. Biosci. 10: 189-191.

14. Maanen, van C. 2002. Vet. Quarterly 24: 57-78.

15. Montali, R. J., Allen, G. P., Bryans, J. T. and Bush, M. 1985. J. Am. Vet. Med. Assoc. 187: 1248-1249.

16. Nairta, M., Uchimura, A., Kumura, K., Tanimura, N., Yanai, T., Masegi, T., Fukushi, H. and Hirai, K. 2000. Vet. Pathol. 37: 476-479.

17. Rebhun, W. C., Jenkins, D. H., Riis, R. C., Dill, S. G., Dubove, E. J. and Torres, A. 1988. J. Am. Vet. Med. Assoc. 192: 953956.

18. Taniguchi, A., Yanai, T., Masegi, T., Yamaguchi, T. and Hirai, K. 2000. Arch. Virol. 145: 2619-2627.

19. Thompson, J. D., Higgins, D. G. and Gibson, T. J. 1994. Nucleic Acids Res. 22: 4673-4680.

20. Yanai, T., Tujioka, S., Sakai, H., Fukushi, H., Hirai, K. and Masegi, T. 2003. J. Comp. Pathol. 128: 113-118.

21. Yanai, T., Fujishima, N., Fukushi, H., Hirata, A., Sakai, H. and Masegi, T. 2003. Vet. Pathol. 40: 263-267.

22. Wolff, L., Meehan, Th. P., Basgall, E. J., Allen, G. P. and Sundberg, J. P. 1986. J. Am. Vet. Med. Assoc. 9: 1185-1186. 